\section{Microbial keratitis}

\section{B H Jeng, S D McLeod}

\section{Shiffing trends in the epidemiology of infectious keratitis demand that we approach all cases thoughtfully}

M icrobial keratitis is a potentially vision threatening condition that requires prompt diagnosis and treatment to prevent untoward outcomes. The incidence of this condition varies from 11.0 per 100000 person years in the United States ${ }^{1}$ to 799 per 100000 person years the developing nation of Nepal. ${ }^{2}$ Microbial keratitis is thus a significant public health problem, and numerous studies have been performed describing the microbiology of corneal infection. As would be expected, there are regional differences in the organisms that are cultured from infected corneas, but for the most part, in the United States, Staphylococcus species seem to predominate.

On a global level, predisposing risk factors for microbial keratitis vary tremendously with geographical location. Although non-surgical trauma to the eye accounted for $48.6-65.4 \%$ of all corneal ulcers in the developing countries of Nepal and India, $^{2-3}$ at a large county trauma referral centre in the United States, non-surgical eye trauma accounted for only $27 \%$ of all cases. ${ }^{4}$ In the United States it is contact lens wear that has emerged as a major risk factor for microbial keratitis. The reported percentage of corneal ulcers associated with contact lens wear has increased in the general population from $0 \%$ in the 1950 s and 1960 s, to $31 \%$ in the 1970 s, and to $52 \%$ in the 1980 s. $^{1}$ In our own community based population study during the late 1990s, we found a continuation of this upward trend with 55\% of corneal ulcers associated with contact lens wear (unpublished data).

Similarly, in academic referral institutions in the United States, there was a well documented upward trend in the incidence of contact lens related corneal ulcers from $9 \%$ in the late 1970 s to $44 \%$ in the late 1980s. ${ }^{5-11}$ However, later reports showed a declining trend to $9-18 \%$ in the late 1990 s. $^{12-13}$ This reduction in corneal ulcers seen at academic referral centres coincident with an increase in the community might be attributed to more successful community treatment of ulcers since the introduction of the topical fluoroquinolones ciprofloxacin and ofloxacin in the 1990s. ${ }^{13-17}$
In this issue of the BJO ( $\mathrm{p} 834$ ), Bourcier et al have reported that contact lens wear accounted for over half of all cases of bacterial keratitis in their study. Although the study originates from a large ophthalmic centre that provides tertiary care, most $(76 \%)$ of the cases presented for the first time in their emergency room, and only $24 \%$ were referred by either general practitioners or ophthalmologists. In this mostly nonreferral based population, the finding of over $50 \%$ of cases of bacterial keratitis being contact lens related is consistent with the previously mentioned community based studies from the United States. As the authors discuss, however, some of the suspected cases of contact lens related bacterial keratitis may actually include contact lens related sterile inflammatory infiltrates that resolve spontaneously upon discontinuation of contact lens wear, rather than true cases of bacterial keratitis. Thus, the authors may have undercalculated the culture positivity rate and overcalculated the percentage of cases of bacterial keratitis with contact lens wear as a risk factor.

\section{Emerging resistance to \\ fluoroquinolones continue to mount both within and outside the sphere of ophthalmology}

It is interesting that in this study, while there were more culture positive contact lenses and/or storage cases than culture positive corneal scrapings, similar bacteria were isolated from the two sources in only $25 \%$ of all cases. This demonstrates that while organism recovery from a lens or case may be easier than from the cornea, the identity of organisms recovered from the contact lens and case cannot be considered a reliable guide for directing antimicrobial therapy. As was shown in this study and has been demonstrated by previous studies, contact lens storage containers are frequently contaminated, commonly with Gram negative organisms. While it has been recognised that Gram negative organisms such as Pseudomonas aeruginosa are associated with contact lens related corneal ulcers, Gram positive organisms such as Staphylococcus species and Streptococcus species have also often been shown to be responsible for a significant portion of these ulcers even when Gram negative organisms are recovered from the lens and case. Indeed, the current study reports a higher incidence of Gram positive organisms than Gram negative organisms recovered from infections associated with contact lens wear. Thus, exclusive reliance on culture data from contact lenses and/or cases may result in suboptimal treatment of corneal ulcers.

Bourcier et al, as well as most authors of studies from academic referral centres, followed the textbook practice of scraping of all suspected cases of microbial keratitis for smear and culture. Since the Gram stain might fail to reveal culpable organisms and it is inadvisable to delay treatment while awaiting the results of cultures, it is common practice to begin empirical treatment with broad spectrum antibiotic drops. Treatment can then be modified later based on clinical response and, if necessary and available, on culture results. Traditionally, specially prepared fortified combined antibiotics were used to provide broad spectrum coverage, but the limited availability, cost, and inconvenience of these fortified preparations have led many academic and community based ophthalmologists to embrace the use of the commercially available topical fluoroquinolones (ciprofloxacin, ofloxacin and, more recently, levofloxacin) since their introduction in the 1990s. These antibiotics have good ocular penetration and provide broad spectrum coverage against most aerobic Gram negative and Gram positive bacteria. They also are safe, do not require refrigeration, and are easily available. In addition, many clinical studies have demonstrated excellent efficacy of these drugs in treating bacterial keratitis. ${ }^{15-17}$ In a questionnaire based study, $82 \%$ of a random sampling of non-cornea fellowship trained ophthalmologists reported that they would treat less severe cases of suspected bacterial keratitis with a single fluoroquinolone, and 62\% reported that they would treat more severe cases in this manner. ${ }^{18}$ Our own study of corneal ulcers in a non-referral based population found that $75 \%$ of corneal ulcers were in fact treated with a single fluoroquinolone agent (unpublished data).

Although there has always been a known gap in coverage for Streptococcus species by the second generation fluoroquinolones, emerging resistance of Staphylococcus aureus to ciprofloxacin and ofloxacin $^{19-20}$ has raised concern over the use of monotherapy with these agents for suspected cases of bacterial keratitis. This is especially true given the high rates of microbial keratitis caused by Gram positive organisms. It is well recognised that the levels of drugs in the cornea obtained with topical therapy far 
exceed minimum inhibitory concentration (MIC) levels as measured in the laboratory based on expected serum levels of antibiotic. Thus, many organisms can be eradicated by an antibiotic to which they are reportedly resistant, and it has been documented that infection by "resistant" organisms treated by a fluoroquinolone alone required a change in therapeutic regimen due to clinical failure only approximately $10 \%$ of the time. $^{19}$

Nevertheless, along with assessments of resistance based on MIC tests, reports of an increasing incidence of clinical failure because of emerging resistance to fluoroquinolones continue to mount both within and outside the sphere of ophthalmology. A role for pretreatment scrapings for laboratory testing therefore persists, even in the age of ever more potent empirical treatment afforded by the newest fluoroquinolones. Based on the microbiological data provided by Bourcier et al, it is of interest that the ophthalmic fluoroquinlone preparations now entering practice, gatifloxacin and moxifloxacin, show particular strengths with regard to activity against Gram positive organisms, a significant cause of morbidity even in the setting of contact lens related keratitis. It remains to be seen whether the relative reduction in Gram negative activity will allow monotherapeutic application or, if combination with a second generation fluoroquinolone, will be required to maintain effective empirical coverage of that group of organisms.

Initial treatment of suspected cases of microbial keratitis with topical fortified antibiotics has long been the gold standard for management of the most severe manifestations of this condition, and the role for fluoroquinolone monotherapy for these and less severe cases continues to be debated. However, if one can propose that the "optimal" management of microbial keratitis is that which is the most convenient for both the patient and the physician, the most cost effective, and the most efficacious, then the "optimal" management strategy is as yet undefined. In spite of the advances in antibiotic pharmacology, shifting trends in the epidemiology of infectious keratitis demand that we approach all cases thoughtfully. Studies such as that provided by Bourcier et al provide most valuable information to this end.

\section{ACKNOWLEDGEMENT}

Support: Heed Ophthalmic Foundation Fellowship, Cleveland, Ohio (BHJ).

Br J Ophthalmol 2003;87:805-806

\section{Authors' affiliations}

B H Jeng, S D McLeod, The Francis I Proctor Foundation and the Department of

Ophthalmology, University of California San Francisco Medical Center, San Francisco, CA, USA

Correspondence to: Stephen D McLeod, MD Cornea and Refractive Surgery Service, Department of Ophthalmology, 10 Kirkham Street, K-301, University of California, San Francisco, San Francisco, CA 94143, USA; smcleod@itsa.ucsf.edu

\section{REFERENCES}

1 Erie JC, Nevitt MP, Hodge DO, et al. Incidence of ulcerative keratitis in a defined population from 1950 through 1988. Arch Ophthalmol 1993;111:1665-71.

2 Upadhyay MP, Karmacharya PC, Koirala S et al. The Bhaktapur eye study: ocular trauma and antibiotic prophylaxis for the prevention of corneal ulceration in Nepal. Br J Ophthalmol 2001;85:388-92.

3 Srinivasan M, Gonzales CA, George C, et al. Epidemiology and aetiologic diagnosis of corenal ulceration in Madurai, south India. $\mathrm{Br}$ J Ophthalmol 1997:81:965-71.

4 Ormerod LD, Hertzmark E, Gomez DS, et al. Epidemiology of microbial keratitis in Southern California. A multivariate analysis. Ophthalmology 1987;94:1322-33.
5 Musch DC, Sugar A, Meyer RF. Demographic and predisposing factors in corneal ulceration.

6 Schein OD, Ormerod LD, Barraquer E, et al. Microbiology of contact lens-related keratitis. Cornea 1989;8:281-5.

7 Gudmundsson OG, Ormerod LD, Kenyon $\mathrm{KR}$, et al. Factors influencing predilection and outcome in bacterial keratitis. Cornea 1989;8: 115-21.

8 Galentine PG, Cohen EJ, Laibson PR, et al. Corneal ulcers associated with contact lens wear. Arch Ophthalmol 1984;102:891-4.

9 Donnenfeld ED, Cohen EJ, Arentsen JJ, et al. Changing trends in contact lens associated corneal ulcers: overview of 116 cases. CLAO J 1986;12:145-9

10 Cohen EJ, Gonzales C, Leavitt KG. Corneal ulcers associated with contact lenses including experiences with disposable lenses. CLAO J 1991;17:173-6.

11 Laibson PR, Cohen EJ, Rajpal RK. Corneal ulcers related to contact lenses. CLAO J 1993;19:73-8.

12 Cohen EJ, Fulton JC, Hoffman CJ, et al. Trends in contact lens-associated corneal ulcers. Cornea 1996;15:566-70.

13 Rattanatam T, Heng WJ, Rapuano CJ, et al. Trends in contact lens-related corneal ulcers. Cornea 2001;20:290-4

14 Parks DJ, Abrams DA, Sarfarazi FA, et al. Comparison of topical ciprofloxacin to conventional antibiotic therapy in the treatment of ulcerative keratitis. Am J treatment of ulcerative keratitis.
Ophthalmol 1993;115:471-7.

15 O'Brien TP, Maureen MG, Fink NE, et al. Efficacy of ofloxacin versus cefazolin and tobramycin in the therapy for bacterial keratitis. Arch Ophthalmol 1995;113:125760.

16 Hyndiuk RA, Eiferman RA, Caldwell DR, et al. Colmparison of ciprofloxacin ophthalmic solution $0.3 \%$ to fortified tobramycin-cefazolin in treating bacterial corneal ulcers. Ophthalmology 1996;103:1854-63.

17 The Ofloxacin Study Group. Ofloxacin montherapy for the primary treatment of microbial keratitis: A double-masked, randomized, controlled trial with conventional dual therapy. Ophthalmology 1997; 104: 1902-9.

18 McLeod SD, DeBacker CM, Viana MAG. Differential care of corneal ulcers in the community based on apparent severity. Ophthalmology 1995;103:479-84.

19 Goldstein MH, Kowalski RP, Gordon YJ. Emerging fluoroquinolone resistance in bacterial keratitis. A 5-year review. Ophthalmology 1999;106:1313-8.

20 Alexandrakis G, Alfonso EC, Miller D. Shifting trends in bacterial keratitis in South Florida and emerging resistance to fluoroquinolones. Ophthalmology 2000;107: 1497-502.

\section{Does human papillomavirus cause pterygium?}

\section{T W Reid, N Dushku}

\section{$\mathrm{HPV}$ is not necessary for the formation of a pterygium}

$\mathrm{H}$ uman papillomavirus (HPV) is the only DNA tumour virus where a large body of evidence implicates it in human cancers. The evidence for a causative role of HPV in human cervical cancer, was recently reviewed by zur
Hausen, ${ }^{1}$ and is the following: (1) expression of specific HPV genes (such as E6 and E7) were shown in cervical cancer cell lines and cancer biopsies ${ }^{2} ;(2)$ viral DNA was shown to have immortalisation properties ${ }^{34}$; (3) viral oncogene expression was shown to be required for the maintenance of the malignant phenotype in specific cervical cancer cell lines ${ }^{56}$; (4) a substantial number of epidemiological studies have been performed which point to high risk HPV as a primary risk factor for cervical cancer. In addition, large case-control and prospective epidemiological studies supported this idea, and indicated that persisting HPV infections were the most significant risk factor in cervical cancer. $^{78}$

Different types of HPV have been identified in a high percentage of nonmelanoma skin cancers (basal and squamous cell carcinomas). However, these basal and squamous cell carcinomas occur preferentially in light exposed sites. This could suggest an interaction 
between ultraviolet light and a low risk (non-mutagenic) papillomavirus infection. ${ }^{9}$ This would make it a possible candidate in pterygia, which are thought to have aetiology involving ultraviolet irradiation.

The binding to the $\mathrm{p} 53$ protein of the E6 oncoprotein, encoded by HPV types 16 and 18 , results in the rapid degradation of p53 protein through the ubiquitin mediated pathway. This HPV infection mechanism leads to a damaged p53 dependent programmed cell death pathway, ${ }^{10} 11$ which is similar to that caused by mutations in the p53 gene. Low levels of normal nuclear $\mathrm{p} 53$ protein permit mutations in other genes to accumulate and allow the multistep development of tumours. Also, reduced bioavailability of $\mathrm{p} 53$ protein has been shown to be a key regulatory event in perturbation of CD95 signalling in HPV16 immortalised keratinocytes. ${ }^{12} \mathrm{HPV}$ and p53 overexpression also commonly coexist in oropharngeal carcinomas, ${ }^{13}$ penile carcinomas, ${ }^{14}$ grade III cervical intraepithelial neoplasia, ${ }^{15}$ and invasive squamous cell carcinomas of the cervix. ${ }^{15}$ Since increased nuclear p53 expression without apoptosis was found in the limbal epithelium of pterygia, limbal tumours, and most pingueculae, ${ }^{16}$ this would be consistent with HPV playing a part in the formation of pterygia.

The paper by Piras et al, in this issue of the $B J O(\mathrm{p} 864)$, shows a $100 \%$ incidence $(17 / 17)$ of HPV in pterygia from Italian cases and a $21 \%(5 / 24)$ incidence from Ecuadorean cases. A recent study by Gallagher et $a l^{17}$ showed a $50 \%$ (5/10) incidence of HPV in pterygia in the United Kingdom. Detorakis et $a l^{18}$ found 15 pterygia contained type $18 \mathrm{HPV}$, for a total of $30 \%(15 / 50)$ in Greece. In addition they found that $8 \%$ of the associated conjunctiva contained HPV (4/50). In other studies Dolmetsch et a $l^{19}$ found HPV-16 in $100 \%$ of their pterygia (16/16) from Canada using immunohistochemical techniques.

The above results are in contrast with the results of McDonnell et al, ${ }^{20}$ who found HPV-16 in $88.1 \%(37 / 42)$ of their patients with conjunctival epithelial neoplasia but none in six pterygia from America. Dushku et $a l^{21}$ also found no evidence of HPV in 13 pterygia and 10 limbal tumours from American cases. McDonnell et al ${ }^{20}$ also found HPV in tissue swabs from eyes with no visible lesions in $66.7 \%(4 / 6)$ of patients with unilateral conjunctival epithelial neoplasia and in one patient who showed a persistence of infection many years after successful eradication of the lesion. This is consistent with the finding of Karcioglu and Issa ${ }^{22}$ who found HPV in 57\% of in situ squamous cell carcinomas, 55\% of invasive squamous cell carcinomas; however, they also found HPV in nonneoplastic lesions $(20 \%$ of climatic droplet keratopathy and $35 \%$ of scarred corneas) as well as $32 \%$ of normal conjunctival tissue obtained during routine cataract extractions. Thus, it would appear that HPV is not required for a pterygium and that even in its presence it cannot act alone in the development of conjunctival epithelial neoplasia.

At the moment several companies and research laboratories are carrying out preclinical and clinical trials of vaccines against high risk HPV. ${ }^{23-25}$ Since experiments with purified papillomavirus structural proteins as vaccines showed protection against the primary infection of dogs and rabbits, ${ }^{26}{ }^{27}$ an effective prevention can also be expected for the human vaccine. If this is true it may allow us to know whether prevention of HPV decreases or blocks the incidence of different cancers. It would also be of interest to see whether vaccinated individuals show a lower incidence of pterygia.

Since Koch's postulates cannot be fulfilled and unless more definitive results are obtained such as those from future HPV vaccine trials, we can only make the following statements for the role of HPV in the occurrence of pterygia: (1) HPV is not necessary for the formation of a pterygium; (2) it is unlikely that HPV can act as the sole cause of a pterygium; (3) HPV may have a role in the formation of some pterygia; (4) pterygia and limbal dysplasias in the interpalpebral area, which regress after topical antiviral treatment with interferon $\alpha 2 b$, may be due to HPV. ${ }^{28}$

\section{Br J Ophthalmol 2003;87:806-808}

\section{Authors' affiliations}

T W Reid, Ophthalmology Department, Texas Tech University HSC, Lubbock, TX 79430, USA N Dushku, Ophthalmology Department, Kaiser Permanente Medical Center, Sacramento, CA 95815, USA

Correspondence to: Professor Ted W Reid Ophthalmology Department, Texas Tech University HSC, Lubbock, TX 79430, USA ted.reid@Huhsc.edu

\section{REFERENCES}

1 Zur Hausen H. Papillomaviruses and cancer: from basic studies to clinical application. Nature Reviews Cancer 2002;2:342-350.

2 Schwartz E, Freese UK, Gissmann L, et al. Structure and transcription of human papillomavirus type 18 and 16 sequences in cervical carcinoma cells. Nature

1985;314:111-114.

3 Durst M, Dzarlieva-Petrusevska RT, Boukamp $P$, et al. Molecular and cytogenetic analysis of immortalized human primary keratinocytes obtained after transfection with human papillomavirus type 16 DNA. Oncogene 1987; 1:251-6.

4 Pirsi L, Yasumoto S, Fellery $M$, et al. Transformation of human fibroblasts and keratinocytes with human papillomavirus type 16 DNA. J Virol 1987;61:1061-6.

5 Von Knebel Doeberitz M, Rittmuller C, zur Hausen $\mathrm{H}$, et al. Inhibition of tumorigenicity of cervical cancer cells in nude mice by HPV E6-E7 antisense RNA. Int J Cancer 1992;51:831-4.
6 Von Knebel Doeberitz M, Rittmuller C, Aengeneyndt $F$, et al. Reversible repression of papillomavirus oncogenes expression in cervical carcinoma cells: consequences for the phenotype and E6-p53 and E7-pRb

interactions. J Virol 1994;68:281 1-21.

7 Munoz N, et al. The causal link between human papillomavirus and invasive cervical cancer: a population-based case-control study in Columbia and Spain. Int J Cancer 1992:52:743-9.

8 Bosch FX, Manos MM, Munoz N, et al. Prevalence of human papillomavirus in cervical cancer: a worldwide perspective. International biological study on cervical cancer (IBXCC) Study Group. J Natl Cancer Inst 1995;87:796-802.

9 Zur Hausen H. Papillomavirus infections B a major cause of human cancers. Biochim Biophys Acta 1996;1288:F55-78

10 Kessis TD, Slebos RJ, Nelson WG, et al. Human papillomavirus 16 E6 expression disrupts the p53-mediated cellular response to DNA damage. Proc Natl Acad Sci USA 1993;90:3988-92

11 Foster SA, Demers GW, Etscheid BG, et al. The ability of human papillomavirus E6 proteins to target p53 for degradation in vivo correlates with their ability to abrogate actinomycin D-induced growth arrest. J Virol 1994:68:5698-705.

12 Aguilar-Lemarroy A, Garglio P, Whitaker NJ, et al. Restoration of $\mathrm{p} 53$ expression sensitizes human papillomavirus type 16 immortalized human keratinocytes to CD95-mediated apoptosis. Oncogene 2002;21:165-75.

13 Barten M, Ostwald C, Milde-langosch K, et al. HPV DNA and p53 alterations in oropharyngeal carcinomas. Virchows Arch 1995;427: 153-7.

14 Lam KY, Chan, AC, Chan KW, et al. Expression of p53 and its relationship with human papillomavirus in penile carcinomas. Eur J Surg Oncol 1995;21:613-16.

15 Akasofu M, Oda Y. Immunohistochemical detection of p53 in cervical epithelial lesions with or without infection of human papillomavirus types 16 and 18 . Virchows Arch 1995;425:593-602.

16 Dushku N, Reid TW. p53 expression in altered limbal basal cells of pingueculae, pterygia, and limbal tumors. Curr Eye Res 1997;16:1179-92.

17 Gallagher MJ, Giannoudis A, Herrington CS, et al. Human papilloma virus in pterygium. $\mathrm{Br}$ J Ophthalmol 2001;85:782-4.

18 Detorakis ET, Sourvinos G, Spandidos DA Detection of herpes simplex virus and human papilloma virus in ophthalmic pterygium. Cornea 2001;20: 164-7.

19 Dolmetsch AM, Alcocedr CE, Scull JJ, et al. The presence of human papillomavirus in pterygia. Invest Ophthalmol Vis Sci (abstract) 1996;37:S43.

20 McDonnell JM, McDonnell PJ, Sun YY Human papillomavirus DNA in tissues and ocular surface swabs of patients with conjunctival epithelial neoplasia. Invest Ophthalmol Vis Sci 1992;33:184-9.

21 Dushku N, Hatcher S, Albert DM, et al. p53 expression and relation to human papillomavirus infection in pingueculae pterygia, and limbal tumors. Arch Ophthalmol 1999:117:1593-9.

22 Karcioglu ZA, Issa TM. Human papillomavirus in neoplastic and non-neoplastic conditions of the external eye. Br J Ophthalmol 1997;81:595-8.

23 Zhou J, Sun XY, Stenzel DJ, et al. Expression of vaccinia recombinant HPV $16 \mathrm{~L} 1$ and L2 ORF proteins in epithelial cells is sufficient for assembly of HPV virion-like particles. Virology $1991 ; 185: 251-7$

24 Zhang LF, Zhou J, Chen S, et al. HPV 6b virus like particles are potent immunogens without adjuvant in man. Vaccine 2000;18:1051-8. 
25 Harro CD, Pang YY, Roden RB, et al. Safety and immunogenicity trial in adult volunteers of a human papillomavirus $16 \mathrm{~L} 1$ virus-like particle vaccine. J Natl Cancer Inst 2001;93:284-92.

26 Suzich JA, Ghim SJ, Palmer-Hill FJ, et al. Systemic immunization with papillomavirus L1 protein completely prevents the development of viral mucosal papillomas. Proc Natl Acad Sci USA 1995;92:11553-7.

27 Breitburd F, Kirnbauer R, Hubbert NL, et al Immunization with virus-like particles from cottontail rabbit papillomavirus (CRPV) can protect against experimental CRPV infection. J Virol 1995;69:3959-63.

\section{Responding to readers' and authors' needs}

\section{Andrew D Dick, Creig Hoyt}

\section{Future changes to the $B J O$}

A s editors, keeping a pace with changes in publishing, pleasing both readers and authors without creating chaos or anarchy is challenging. We continue to respond to the voices of both readers and authors alike and will continue as such to change the journal format to maintain and fulfil its mission of supplying high quality information in its most relevant and readable form. We acknowledge that the readers and authors may have different expectations of the journal. Firstly, readers wish to be assisted in their continual professional development and revalidation and require easy access to information that is readable and succinct. Secondly, there is a need to assist researchers with information pertinent to their individual needs and, thirdly, of course, we need to give the authors the medium to present their findings and views in the most expeditious manner and which will sell to the widest audience.
As such, the BJO is committed, along with the rest of the BMJ Publishing Group, to provide a medium to satisfy all. Although the $B J O$ has seen a dramatic increase in submissions, now over 1300 articles a year, with an acceptance rate of $34 \%$, going online has enabled our mean time to decisions on papers to be cut drastically to three weeks. We aim to please authors further within the next 12 months as we launch the capability to publish manuscripts as soon as they are accepted-on the website-followed in print by the technically edited version a few months later. This will provide immediate dissemination of up to date work to all. In addition, this will hopefully create fruitful correspondence, which will be all web based; you will be asked to submit your correspondence (Mailbox) directly to eBJO. We will also increase page provision in the print journal to ensure that print publication time is around four months from acceptance.
28 Maskin SL. Regression of limbal epithelial dysplasia with topical interferon [letter]. Arch Ophthalmol 1994;112:1145-6.

29 Fung-Rong $\mathbf{H}$, Ming-Jet W, Sow-Hsong, K. Interferon treatment for corneolimbal squamous dysplasia. Am J Ophthalmol 1998;125:118-119.
What about the readers? The $B M J$ has reiterated from its studies that readers do not read traditional long full original articles, and the need for such articles to be so long has been questioned. We wish to encourage articles that are written succinctly and, in time, we will be providing a modified "Instructions to authors" that will have link sites to assist prospective authors less experienced in writing. The articles will be divided into Clinical science and Laboratory science as is the case at present and, within each section, there will be the opportunity to submit either extended or scientific reports. There will be strict word counts of 3000 and 1500 words, respectively, and we will be encouraging authors where appropriate to submit their work in the shorter version. Letters to the editor will remain but we will be focusing our attention, because of priority and space, on case series, genetic reports, and clinicopathological reports. Perspectives will also remain but again will be limited strictly to 4000 words. We still encourage and solicit editorials, commentaries, and world views and maintain our commitment towards globalisation, publishing work from, and provision of information to all.

Br J Ophthalmol 2003;87:808

\section{Authors' affiliations}

A D Dick, C Hoyt, Editors; choył@itsa.ucsf.edu 